\title{
Pesticide tests on humans cause concern
}

[WASHINGTON] The US Environmental Protection Agency (EPA) said last week that it was "deeply concerned" that some pesticide manufacturers appeared to be engaging in health-effects studies on human subjects "as a way to avoid more protective results from animal tests".

The statement came as it emerged that a Californian pesticide company has helped to pay for a study at the University of California, Davis, of human volunteers who were exposed to methyl isothiocyanate, the active ingredient in metam sodium, a potent soil fumigant (see box).

The company, Amvac Chemical Corporation, belonged to a coalition of six chemical companies - including Zeneca Ag Products - which spent roughly half a million dollars on the experiment, designed to meet California regulations. The study was carried out in 1994 and involved 70 paid volunteers.

Revelations last week that the same company had funded human experiments on British volunteers of an organophosphate pesticide, dichlorvos, have already focused attention in both Washington and London on a previously little-asked question: should pesticide makers be allowed to carry out tests on human volunteers to provide data to federal regulators, and, if so, under what conditions?

In response to news of the US-funded tests in Britain, the EPA said in a statement that "no human test data have been used by EPA for any final decisions about acceptable levels of pesticide use" under new food safety laws that critics claim the companies are trying to circumvent through human testing. (California's approach appears less stringent).

According to Ken Cook, president of the Washington-based Environmental Working Group (EWG), which advocates tougher pesticide controls, the Californian study is the first known pesticide experiment to have been conducted on human volunteers in the United States in recent years. He describes the experiment as further evidence that the EPA "needs to turn on its radar system and find out the extent of human experimentation on pesticides".

The British tests were described in a report by EWG that documents the testing on humans of dichlorvos for Amvac by the Medeval Laboratories in Manchester in 1997. The Guardian newspaper reported this week that human tests were still being carried out on the organophosphate insecticide azinphos-methyl by the Inveresk Clinical Laboratory in Scotland, for which students and others were being paid $\$ 480$ (US\$780).

In its report, EWG criticizes the EPA for using data from the British experiments in determining pesticide safety levels, and calls for a moratorium on the use of human data in pesticide regulation. "EPA is accepting and evaluating human experimental studies that it does not require and, in fact, actively discourages," the report says.

The EWG report contends that EPA used the human data in deciding to relax the safety margins for aldicarb. The group also alleges that industry is deliberately using human data to circumvent the tougher safety standards required in the Food Quality Protection Act of 1996, which overhauled pesticide regulation. By testing on humans, it says, companies hope to avoid an extra, tenfold margin of safety in determining safe exposure levels.

The EWG report also criticizes the EPA for failing to ensure that pesticide companies abide by government ethics rules — the socalled Common Rule for human subjects' protection — adopted by the agency in 1991.

Amvac defends the use of humans in experiments by arguing that it meets the conditions in the Helsinki Declaration for Testing and Protection of Human Subjects, requiring informed consent of participants and approval by independent ethics boards.

Ian Chart, the company's director of regulatory affairs, says that testing pesticides on humans "is good science when carried out under the Declaration of Helsinki", which makes no distinction between the testing of pharmaceuticals and pesticides.

The company points out that dichlorvos, the pesticide used in the Manchester experiment, has been used for about 30 years to treat schistosomiasis.

MeredithWadman

\section{[WASHINGTON] In tests}

conducted at the University of California in Davis for Amvac, Zeneca and other chemical companies (see above), investigators sought to determine the levels at which methyl isothiocyanate (MITC), the active ingredient in the pesticide metam sodium, can be smelt, and those at which it produces physiological effects.

Eye irritation was measured by running varying concentrations of MITC vapour into goggles worn by volunteers for between one minute and eight hours. Tearing, blinking, subjective discomfort and redness were measured. The study found "no significant increases" in redness or tearing for most test subjects; irritation was deduced from blink rates and subjective discomfort.

The lead investigator, Michael Russell, a neurobiologist at the university's medical school, says the study - which was filed with the state government in September 1996 - produced "no ill effects whatsoever". Russell, who himself volunteered, says the study was approved without problem by the institutional review board at the medical school. He estimates that volunteers were paid $\$ 150$ or $\$ 300$, depending on how long they spent wearing the goggles.

MITC - a less potent cousin of methyl isocyanate, the agent in the Bhopal disaster - is a toxic fumigant that kills virtually all soil organisms. Farmers use it to strip the soil of weeds, insects and microbes before planting. In humans, at high concentrations, it is very irritating to the eyes, skin and respiratory system.

In recent years, dozens of California residents living near farms using metam sodium have been hospitalized with sore throats, burning eyes, breathing difficulties, headaches, nausea and vomiting. In 1991, a train accident dumped at least 13,000 gallons of the pesticide in the Sacramento river, killing tens of thousands of fish. When tests showed that high doses of metam sodium cause birth defects in rats and rabbits, there were calls to pull it from the market.

The companies funded the Davis study because they were dissatisfied with animal data - in particular, a study of tearing in cats - that were being used by California's Department of Pesticide Regulation (DPR) for risk assessments. Russell says that the companies' interest was "to have an [approved exposure] level that is as high as possible but still actually safe".

Veda Federighi, a DPR spokeswoman, stresses that the department "did not request a human subjects study" from the companies. But she adds, "we would have no problem accepting a [human] study that's done within appropriate guidelines". Federighi says the California DPR applies a tenfold safety factor to anima data to arrive at acceptable human exposure levels.

"Often [companies] feel that that is inappropriate."

Critics say that metam sodium is such a potent poison that the government should be banning it, not using human data to regulate it. "We ought not to be exposing people to try to keep its use legalized," says Ralph Lightstone, a staff attorney with the California Rural Legal Assistance Foundation, an advocacy group for farm-workers.

California's DPR placed restrictions on its use in 1994, but the amount used grew in 1995, the most recent year for which data are available. Zeneca Ag Products, based in Wilmington, Delaware, stopped producing metam sodium recently; Amvac continues to make it, along with dichlorvos (see main story). M.W. 